\title{
First Record of Breeding of the Hawk Owl on the Southern Border of the Breeding Range in the Nizhniy Novgorod Region, Russia
}

\section{ПЕРВАЯ НАХОДКА ГНЕЗДА ЯСТРЕБИНОЙ СОВЫ НА ЮЖНОЙ ГРАНИЦЕ АРЕАЛА В НИЖЕГОРОДСКОЙ ОБЛАСТИ, РОССИЯ}

\author{
Spiridonov S.N. (National Park "Smolny", Smolny, Republic of Mordovia, Russia) \\ Matsyna A.I. (Laboratory of ornithology under Ecological Center "Dront", N. Novgorod, \\ Russia) \\ Kuimov E.V. (N. Novgorod branch, Russian Bird Conservation Union, Lukoyanov, Russia) \\ Спиридонов С.Н. (ФГУ Национальный парк «Смольный», п. Смольный, Республика \\ Мордовия, Россия) \\ Мацына А.И. (Орнитологическая лаборатория НРОО Экологический \\ центр «Дронт», Н. Новгород, Россия) \\ Куимов Е.В. (Нижегородское отделение Союза охраны птиц России, Лукоянов, \\ Россия)
}

\section{Контакт: \\ Сергей Спиридонов alcedo@rambler.ru \\ Александр И. Мацына calidris@mail.ru \\ Евгений Куимов ooofalco@yandex.ru \\ Contact: \\ Sergey Spiridonov alcedo@rambler.ru \\ Alexander Matsyna calidris@mail.ru \\ Evgeniy Kuimov ooofalco@yandex.ru}

Ястребиная сова (Surnia ulula) на гнездовом участке.

Фото С. Спирицонова.

Hawk Owl (Surnia ulula) on the breeding territory.

Photo by S. Spiridonov.

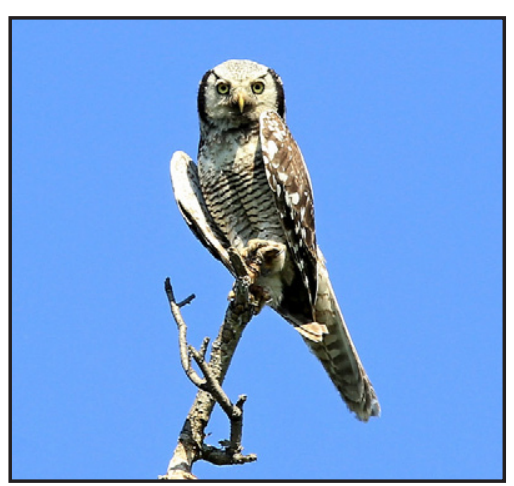

Ястребиная сова (Surnia ulula) - одна из самых редких и малоизученных сов Нижегородской области. Она находится здесь на южной границе ареала, вкиючена в Красную книгу Нижегородской области как неопределённый и недостаточно изученный ви - категория $\Delta$ (Красная книга ..., 2004). Вид также внесён в списки редких видов Рязанской области и Республики МорАовия. Оптимальными местообитаниями ммя ястребиной совы сиужат хвойные и смешанные леса, с преоблацанием берёзы.

Наибольшее число встреч вида в области зарегистрировано на территории Нижегородского Заволжья, гАе птиц наблюдаии преимушественно в осенне-зимний период, как в конце XIX - середине XX вв., так и в конце XX в. (Серебровский, 1918; Воронцов, 1967). Во время сезонных кочёвок, когАа птицы встречаются гораздо шире, чем в гнездовой сезон, известны залёты вида и в правобережье Волги. В частности, есть сообщения о неоднократных зимних встречах ястребиной совы на территории Спасского района НижегороАской области. Зимой 2008 г. зАесь была цобыта взрослая ястребиная сова, чучело которой нахоАится в частной комекции (Мастюгин А.Б., мичное сообшение). В начале зимы 2010 г. ястребиная сова была отмечена на территории Павловского района (Суров С.Г., Аичное сообщение). Зимой 2012 г. ешё одна птица была поймана на территории Нижегородского Кремля и позже отпушена в
Hawk Owl (Surnia ulula) is one of the rarest owl species of Nizhniy Novgorod region of Russia. Here is the southern range of its distribution. From the beginning of 2014, regular meetings with this owl had occurred in Lukoyanovskiy district of Nizhniy Novgorod Region. Owls were seen several times in a birch grove (N 54 $\left.{ }^{\circ} 58^{\prime} \mathrm{E} 44^{\circ} 14^{\prime}\right)$. We found the nest in the same grove during surveying on April 22. The nest situated on the top of a broken trunk of a dead birch at 12-14 $\mathrm{m}$ from the ground. The one bird was hatching, while the second one concealed itself in the forest in $50 \mathrm{~m}$ from the nest. On the second of May, we found eggshells under the nest, and on $13^{\text {th }}$ of May five nestlings of different age were sitting in the nest. During our visit at 17 of May, only three nestlings were in the nest. The two eldest ones have already fledged. One of them was sitting on the earth road not far from the nest, the other one - in the short grass near his sibling.

On the $24^{\text {th }}$ of May we found only one adult bird on the breeding area. As we revealed a bit later, its mate died from electrocution on $10 \mathrm{kV}$ powerline that passed near the grove.

On the $30^{\text {th }}$ of May, we found scattered feathers of juvenile Hawk Owl in the vicinity. We suppose that it also died from electrocution and then was consumed by fourfooted predators.

At the end of July, the powerline was equipped with bird-safety devices.

This observation of the nest of the Hawk Owl is the first documented fact of breeding of this species in the south of Nizhniy Novgorod Region in forest-steppe landscapes, in considerable distance from the known borders of distribution range of this species. 
ГнезАовой биотоп ястребиной совы (вверху), её гнездо (в центре - показано стрелкой) и охотничий биотоп (внизу). Аукояновский район Нижегородской области.

Фото Е. Куимова и С. Спирицонова.

Breeding habitat of the Hawk Owl (upper), its nest (center) and hunting biotope (bottom). Lukoyanovskiy district Nizhniy Novgorod Region, Russia. Photos by E. Kuimov and S. Spiridonov.

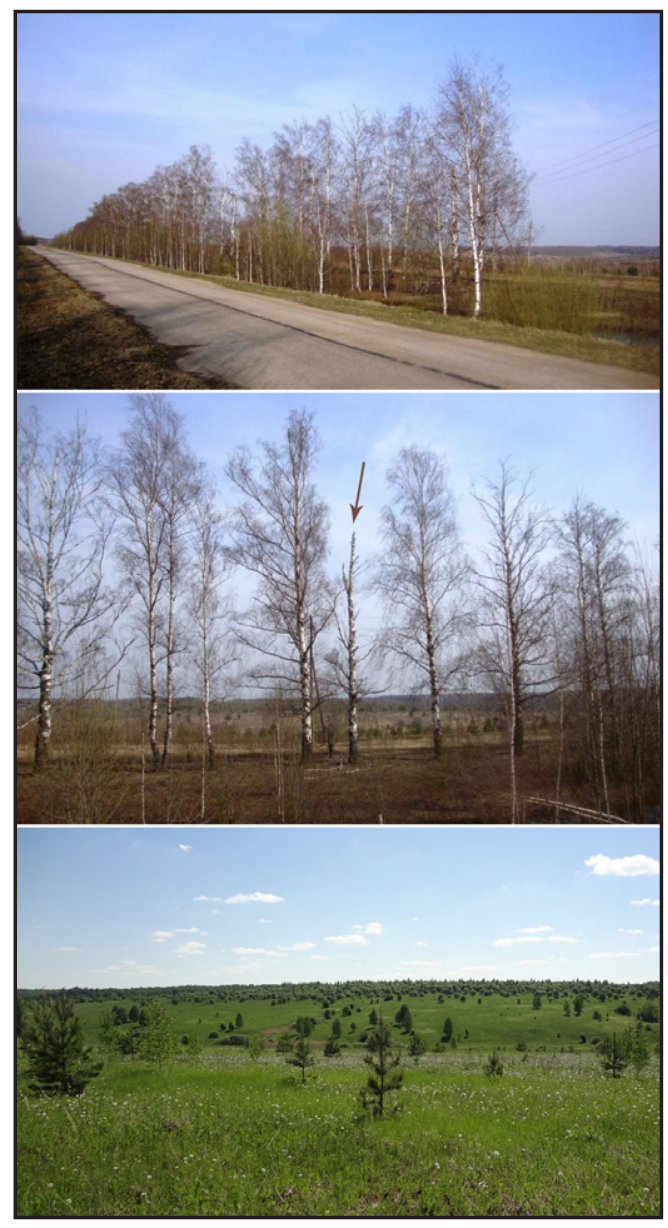

Семеновском районе в окрестностях п. Рустай (Министр..., 2012). В гнезАовой период встречи редки, однако имеются указания на то, что в подходяших местах ястребиная сова гнездится повсеместно, но редко (Пузанов и Ар., 1955).

С начал 90-х гг. XX столетия Ао 2003 г. вкиючительно была известна только одна встреча взрослой птицы в гнездовое время в Сокольском районе в конце июня-начале июля 1995 г. (Красная книга ..., 2004). Плотность гнездования ястребиной совы в пределах Нижегородской области оценивалась в 0,01 пар/100 км² (Бакка, Киселёва, 2004). По состоянию на 2006 г. ястребиная сова мия Нижегородской области приводилась в статусе нерегулярно гнезАяшегося вида с одновременным размножением в области в год не более 1-3 пар (Бакка и др., 2006). В начаме июня 2014 г. в Шахунском районе найден слёток ястребиной совы (Комаров А.П., мичное сообщение), что указывает на размножение вида в Северном Заволжье. В то же время факты, достоверно подтверждаюшие находку гнёзд вида в регионе, последние 20 лет отсутствовами.

С конца зимы 2014 г. регулярные встречи ястребиной совы стами отмечаться в
Лукояновском районе Нижегородской области (рис. 1, стр. 18). ЕАиновременно УАавалось наблюдать только одну птицу, которая держалась около придорожной берёзовой лесополосы в 2 км юго-запацнее с. Самааманов Майдан (5458' с.ш., 4414' в.А.). Выезды на место встречи вида были регулярными, в том числе и в периоА весенней охоты, с целью проследить и предупредить возможное беспокойство птицы.

Лесополоса, в которой загнездились ястребиные совы, граничит с суходольными лугами, плавно спускаюшимися в приручьевую пойму. Ауга заросли невысокой растительностью, отАельными редкими берёзами и соснами и использовамись совами как охотничий участок. При обследовании данной лесополосы 22 апремя 2014 г. было найдено гнезАо, которое располагалось на вершине слома ствола сухой берёзы на высоте 12-14 м. Аиаметр слома гнездового дерева на уровне роста человека составлял 19 см. Насиживаюшую птицу с трудом можно было заметить с земии, удалось рассмотреть только хвост, слегка раздуваемый ветром. Вторая птица держалась в лесополосе примерно в 50 м от гнезда и с приближением человека улетела.

Совы активно зашишами территорию от Аругих хишных птиц. Так, когАа вАоль лесополосы с гнездом сов пролетел чёрный коршун (Milvus migrans), одна из сов подлетела к нему, предприняв попытку атаковать, и коршуну пришлось изменить направление полёта. В целом, опасность м^я сов представляли только хишные птицы. Врановые, которые также способны нанести вред гнездяшимся ястребиным совам, в ходе наших неоднократных выездов на Аанной территории почти не отмечамись. Аишь однажды в лесополосе, в 100 м от гнезда, отмечена серая ворона (Corvus corone) и один раз вАоль лесополосы, где было гнездо, пролетел ворон (Corvus corax).

В конце апреля около гнезда сов, мяя привлечения мышевидных грызунов, которые могли бы стать Аобычей сов, были высыпаны семена подсолнечника и злаков. ОАнако, в начаме мая прикормка оставалась почти не тронутой, что косвенно указывало на низкую численность грызунов.

При обследовании гнезда 2 мая мы убедились, что сова находится на гнезде - были заметны выглядываюшие наружу голова и хвост. Под гнездом была найдена скорлупа от яйца ястребиной совы. 
Ястребиная сова на гнезце (вверху слева), скорлупа яйца (внизу слева) и окольцованный птенец (справа). Фото Е. Куимова и С. Спиридонова.

Hawk Owl in the nest (upper on the left), eggshells (bottom on the left) and ringed nestling (on the right). Photos by E. Kuimov and S. Spiridonov.

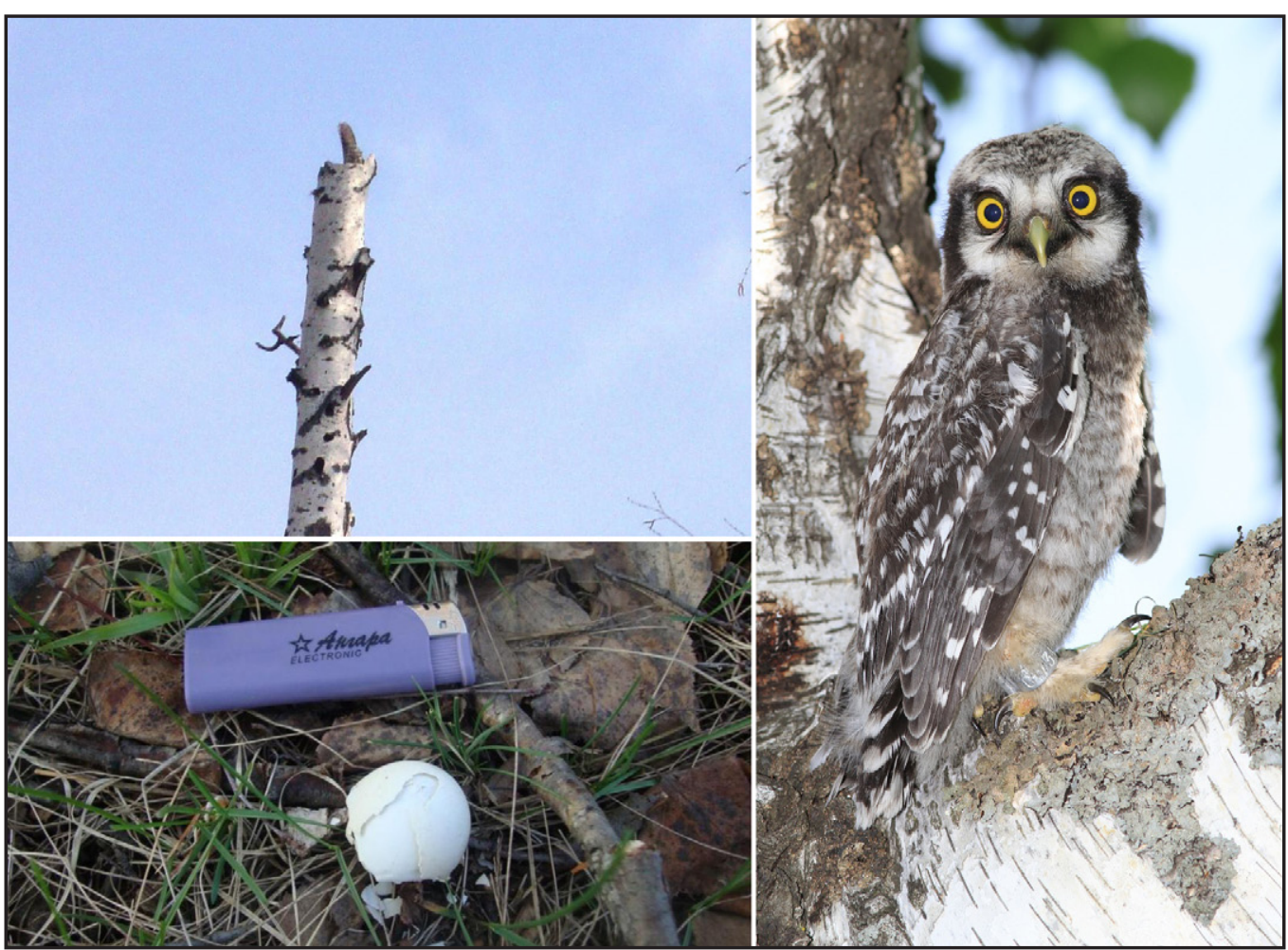

Во время осмотра гнезда 13 мая в нём были обнаружены 5 разновозрастных совят, которые, услышав тревожные крики взрослой птицы, прижимамись ко Ану гнезда. При посешении гнезда 17 мая в нём осталось 3 птенца, а 2 старших птенца вылетели. ОАин из них сидел недалеко от гнезда на грунтовой дороге, а второй - ряАом, в невысокой, редкой траве.

При осмотрах совы предпринимами попытки отводить человека от гнезАа. Так, во время приближения человека к гнезду и осмотра территории вокруг него 17 мая, одна из сов с тревожным криком пролетела в 10 м от наблюдателя, села на дерево и, притворившись раненой, слетела в кусты и затрепетала крылом. При нашем приближении она улетела. Подобное поведение было засиксировано и при обследовании гнезда 21 мая. Все птенцы в это время покинули гнездо. Взрослая птица затрепетала крыльями, находясь на дереве, затем резко слетела вниз на землю и отлетела. В Аругой раз, сидя на столбе ^ЭП, птица спикировала к земле и пролетела низко нал землей, пытаясь отводить человека.

При обследовании гнездового участка 24 мая была отмечена только одна взрослая птица. В этот же день, при обследовании АЭП 10 кВ, проходяшей вАоль лесополосы, под ближайшей к гнезду опорой была обнаружена погибшая от удара током вторая взрослая ястребиная сова (Мацына, Спи- ридонов, в печати). Уцелевшая птица держаяась на вершинах берёз, часто кричала, присаживалась на расположенные рялом с гнездом низкие сосенки и на провода АЭП. Нередко подпускала на 50-70 м. Под гнездом птенцов найдено не было. $\triangle$ ва из

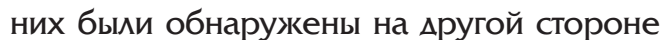
Аороги, в лесополосе. ОАин сидел на боковой ветке берёзы, на высоте 3 м от земли, Аругой находился в 25 м от него на земле. Расстояние Ао гнезда составляло 50 м. Ешё один птенец находился на той же стороне Аороги, гАе было расположено гнезАо, но в 75 м южнее. Он силел на боковой ветке берёзы, на высоте 2 м от земии и в 10 м от полевой дороги. При нашем приближении к нему, подлетела взрослая сова и села на верхушку соседней берёзы. ОАин птенец был окольцован.

У киля прошупываиись небольшие углубления, что говорит о недокормленности птенцов. С учётом гибели одного из родителей, они неизбежно испытывами недостаток в кормлении. Около одного из птенцов на земляных кочках и старых берёзовых пнях было найдено 7 погалок цилиньрической формы Авух размерных категорий (табл. 1), вероятно, взрослой птицы и птенца. Разбор этих погадок показая, что основу питания ястребиной совы составляли мышевидные грызуны. В погадках обнаружены останки 14 обыкновенных полёвок (Microtus arvalis), 1 лес- 
Табл. 1. Размер, вес и состав погацок ястребиной совы (Surnia ulula), 24 мая 2014 г., Аукояновский район.

Table 1. Size, weight and composition of pellets of the Hawk Owl (Surnia ulula). May 24, 2014, Lukoyanovskiy district.

\begin{tabular}{|c|c|c|c|}
\hline № & $\begin{array}{r}\text { Paзмер, мм } \\
\text { Size, } \mathbf{m m} \\
\end{array}$ & $\begin{array}{r}\text { Macca, r } \\
\text { Weight, g }\end{array}$ & $\begin{array}{r}\text { Состав } \\
\text { Composition } \\
\end{array}$ \\
\hline 1 & $4.8 \times 1.9$ & 2.84 & Microtus arvalis - 2 шт./ind. \\
\hline 2 & $4.9 \times 2.2$ & 3.22 & Microtus arvalis - 2 шт./ind. \\
\hline 3 & $4.5 \times 2.0$ & 2.76 & $\begin{array}{l}\text { Microtus arvalis - } 3 \text { шт./ind., } \\
\text { Sicista betulina - } 1 \text { шт./ind. }\end{array}$ \\
\hline 4 & $5.6 \times 2.3$ & 4.28 & $\begin{array}{l}\text { Microtus arvalis - } 4 \text { шт./ind., } \\
\text { Lacerta agilis - } 1 \text { шт./ind. }\end{array}$ \\
\hline 5 & $3.7 \times 1.7$ & 1.21 & Microtus arvalis - 1 шт./ind. \\
\hline 6 & $3.2 \times 1.6$ & 1.23 & Microtus arvalis - 1 шт./ind. \\
\hline 7 & $2.8 \times 1.9$ & 1.02 & Microtus arvalis - 1 шт./ind. \\
\hline
\end{tabular}

ной мышовки (Sicista betulina) и 1 прыткой ящерицы (Lacerta agilis).

При посешении гнезда 27 мая взрослая птица и птенцы находились в пределах гнездового участка. Млацший птенец был отловлен, степень его упитанности была средней.

При очередном осмотре 30 мая в районе гнезда взрослой птицы и птенцов не отмечено, однако в районе гнезда были найдены перья ешё одной погибшей ястребиной совы. СуАя по большому числу растуших перьев - одного из птенцов старшего возраста. Гибель могла наступить в результате напацения пернатого хищника или при поражении электрическим током ^ЭП. Тушка погибшей птицы могла быть впоследствии перемешена и съедена наземным хищником. В пользу этого предположения говорят расшеплённые концы

Слёток ястребиной совы (вверху) и останки погибшей ястребиной совы (внизу). Фото С. Спирицонова и Е. Куимова.

Fledgling of the Hawk Owl (upper) and remains of the dead bird (bottom). Photos by S. Spiridonov and E. Kuimov. некоторых крупных перьев, которые можно различить на снимке.

В конце июля на опорах ^ЭП около гнезАа совы были установлены птицезашитные устройства.

Обследование в конце июля и в середине сентября лесополосы и прилегаюшего участка куга не выявило фрактов нахождения ястребиных сов около гнезАа.

$\triangle$ анная находка гнезда ястребиной совы является первым Аостоверным фактом размножения вида на юге Нижегородской области. Значительная удаиённость от известных границ ареала, а также необычный тип гнездового биотопа (берёзовая лесополоса в окружении открытых ландшасртов) говорят о возможности успешного гнездования ястребиных сов в условиях лесостепной зоны. Намичие в южной части Нижегородской области и в соседних регионах значительных по протяжённости участков старовозрастных берёзовых лесополос, в значительной степени пострацавших во время засухи 2010 г. и последовавшей многоснежной зимы 2010-2011 гг., созАаёт здесь благоприятные условия мия гнезАОвания Аанного вида сов. В значительной степени это подкрепляется и продолжаюшимися процессами зарастания сельскохозяйственных угодий, в современном состоянии наиболее удобных мия ястребиных сов в качестве кормовых стаций.

Авторы выражают благодарность А.В. Андрейчеву (Мордовский университет) за помошь в определении останков грызунов в погадках ястребиной совы.

\section{Митература}

Бакка С.В., Карякин И.В., Киселёва Н.Ю., Новикова 1.М. Новые Аанные о распространении и численности сов в Нижегородской области. - Пернатые хищники и их охрана. 2006. № 5. C. 22-36.

Бакка С.В., Киселёва Н.Ю. Численность и распространение сов в Нижегородской обмасти. - Совы Северной Евразии. М., 2005. C. 214-221.

Воронцов Е.М. Птицы Горьковской области. Горький, 1967. 167 с.

Красная книга Нижегородской области. Т. 1. Животные. Н. Новгород, 2004. 380 с.

Министр спасла ястребиную сову. - Новости Российской сети изучения и охраны пернатых хишников. 2012 (http://rrrcn.ru/ru/ archives/11766).

Пузанов И.И., Козлов В.И., Кипарисов Г.П. Животный мир Горьковской области: (Позвоночные). Горький, 1955. 432 с.

Серебровский П.В. Материалы к изучению орнитосрауны Нижегородской губернии. - Материамы к познанию фауны и фморы России. ОтА. зоол., вып. 15. М., 1918. С. 23-134. 